\title{
How to Use Wind Power Efficiently for Seawater Reverse Osmosis Desalination
}

\author{
Divas Karimanzira \\ Department of Surface Water and Maritime Systems, Fraunhofer IOSB, Ilmenau, Germany \\ Email: divas.karimanzira@iosb-ast.fraunhofer.de
}

How to cite this paper: Karimanzira, D. (2020) How to Use Wind Power Efficiently for Seawater Reverse Osmosis Desalination. Energy and Power Engineering, 12, 499-520. https://doi.org/10.4236/epe.2020.129031

Received: August 3, 2020

Accepted: September 19, 2020

Published: September 22, 2020

Copyright $\odot 2020$ by author(s) and Scientific Research Publishing Inc. This work is licensed under the Creative Commons Attribution International License (CC BY 4.0).

http://creativecommons.org/licenses/by/4.0/ (c) (i) Open Access

\begin{abstract}
Due to water scarcity and the global trends in climate change, winning drinking water through desalination is increasingly becoming an option, especially using reverse osmosis (RO) membrane technology. Operating a reverse osmosis desalination plant is associated with several expenses and energy consumption that take a very large share. Several studies have shown that wind power incurs lower energy costs compared to other renewable energy sources, therefore, should be the first choice to be coupled to an RO desalination system to clean water using sustainable energy. Therefore, in this paper, we investigate the feasibility of driving an $\mathrm{RO}$ desalination system using wind power with and without pressure vessel energy storage and small scale energy recovery using Clark pump based on simulation models. The performance of both variants was compared with several scenarios of wind patterns. As expected buffering and energy recovery delivered higher water production and better water quality demonstrating the importance of an energy storage/recovery system for a wind-power-supplied desalination plant.
\end{abstract}

\section{Keywords}

Wind-Powered Desalination, Energy Storage, Optimal Scheduling, Energy Recovery

\section{Introduction}

Population increase (means increased fresh water demand), water scarcity (fresh water reserves are depleting), global trends in climate change among other things are the drivers for the increased commercialization of winning water by desalination. About $50 \%$ of the desalination system worldwide is based on Reverse Osmosis (RO) [1] [2]. An RO desalination system that is run under standard operating conditions is able to produce a high water flux as well as a salt 
rejection of up to $98 \%$ [2]. Unfortunately, due to the membrane characteristics, the performance is largely affected by the quality of the feed water and the real conditions of operation.

RO processes require high pressures, because the transmembrane pressure should be overcome and this is associated with high energy costs. For these RO systems, main expenses are on energy consumption and cost for maintaining and replacing the membranes, which has a share of $45 \%$ to $50 \%$ of the total water generation [2] [3]. Feo-Garcia et al. stated that according to the feed water quality, the membrane characteristics and the condition under which the plant is operating, $3-8 \mathrm{kWh}$ energy is required to win 1000 liters of permeate [2] [4]. The worldwide appeal for reducing $\mathrm{CO}_{2}$ emissions and the constantly rising prices on fuel makes the priority of using renewable energy to drive desalination plants unavoidable. Furthermore, the cost of energy accounted for transmission and distribution compared to conventional power sources is saved as most wind or solar parks are decentralized and in a microgrid. Therefore, powering a desalination plant with alternative energy sources is worth considering [5].

There have been many studies, in which the reliability and feasibility of utilizing alternative energy sources (PV, Wind, geothermal, tidal, etc.) have been investigated [6] [7] [8] [9]. Energy from PV and Wind has been the most applied to power RO desalination plants [10] [11] [12] [13]. On one hand, albeit the existence of solar powered desalination plants, they require a very high cost of investing capital in the PV arrays, invertors and regulators. On the other hand, power generation by wind incurs lower costs [14] [15] [16] and has proven to be beneficial particularly when the desalination plant is located near coast, where usually frequent high wind speeds occur. The results of the study in Kesherman et al. where the authors studied the benefit of adding PV or Wind power to the grid for desalination, showed that grid plus wind required 32\% less energy from the grid than grid plus solar and the emissions of $\mathrm{CO}_{2}$ gas were lower also and as expected, the result of their cost analysis showed higher additional costs requirement for the integration PV into the grid [17]. However, wind is an intermittent energy source and very unpredictable in nature, so using wind as a reliable source poses man challenges. Therefore, most of the time wind is used an auxiliary source to the grid or it is first converted into electrical energy and the back to mechanical energy which increases the cost and losses [18] [19]. However, they have been some attempts to avoid the use of the grid, for example, Wiener et al. integrated a wind turbine directly to a RO system and positioned a pressure accumulator and a control valve for pressure and flow regulation through the RO membrane [20]. In [21] a variable flow RO system is driven by $2.2 \mathrm{~kW}$ wind power and used a Clark pump for energy recovery from the brine. Their results also gave an indication that direct coupling is feasible.

Powering a desalination with renewable energy sources involves two processes, which are the conversion of the energy, e.g. from wind to power and the desalination process. Therefore, the two processes should be integrated in an optimum way, i.e. to get continuous energy supply from an intermittent source for optimal 
results and this is a very big challenge. Usually to avoid this intermittent characteristic, the two processes are integrated together through a backup system such as a battery, flow/pressure stabilizer, flywheel system which can store or release energy as required [9] [18] [21]. Thomson et al postulated that batteries can cause issues, especially in hot weather conditions, which may cause loss of energy of up to $25 \%$ [22]. The flow/pressure stabilizer is a hydropneumatic tank which can be used to dampen the excessive fluctuations in the energy supply to the pump and maintain steady flow of the feed water for desalination [23]. This system was made for brackish water with a salinity of $2500 \mathrm{mg} / \mathrm{L}$ and therefore, for pressures of $70-105$ psi. Seawater has salinity in the order of 32,000 - 35,000 $\mathrm{mg} / \mathrm{L}$ which requires pressures of the order of $800-1000 \mathrm{psi}$. A wind powered system designed to generate such high pressures could not be found in the literature.

The main goal of this work is to model and show the feasibility of using a wind energy system with or without storage to drive a seawater desalination plant with energy recovery device. A Clark pump was chosen for energy recovery, because it has proven to be suitable for small scale systems [24] [25]. This paper has the following new contributions:

- Study of the effect of energy storage (pressure vessel) in wind-powered desalination plants and development of a strategy to operate the system.

- Optimization of the parameters of the pressure vessel according to the wind pattern.

- Energy recovery for small scale plants using a modified Clark pump.

The rest of the paper is organized as follows. In Section 2, the methodology and all models required for the simulation of the system will be described. Section 3 will give the results and discussions and finally in Section 4 concluding remarks will be given.

\section{Materials and Methods}

The idea is to develop a conceptual model of a wind-powered RO desalination plant which can be run in two modes, mode one, the base case without energy storage mechanism and the second mode with energy storage mechanism. Both systems can be run with energy recovery device activated. The setup of this system is shown in Figure 1. In the second mode, energy buffering is activated and a pressure vessel is connected before the RO unit (Valves 1 and 3 are on and 2 is off). In this case, the high pressure pump will pump the feed water into the energy storage tank where it will get pressurized. From here the pressurized water will be discharged into the RO unit in a controlled manner. As Figure 1 shows, for the energy recovery, seawater flows in from the feed water tank through a common intake, which is split between the Clark pump and the high-pressure pump. The Clark pump and the variable speed high pressure pump are configured to work in parallel, i.e., each pump pressurizes a portion of the feed water flow and their high pressure outputs are then combined before they enter the RO Unit. The brine stream is constantly flowing into the Clack 


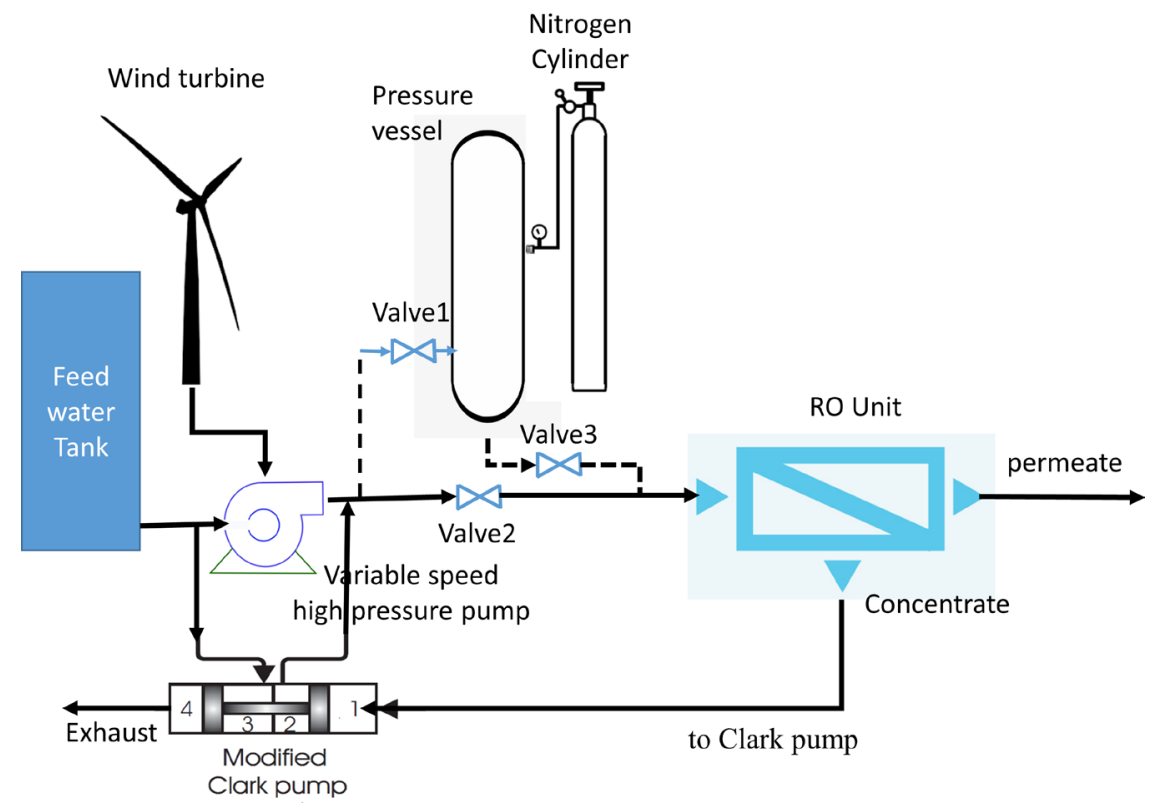

Figure 1. Setup for the RO desalination unit with two modes of operation, with and without energy storage.

pump as shown in Figure 1. The modified Clark pump, which can be used together with a high pressure pump was introduced in [26].

In the experimental setup, several wind scenarios will be fed into the system and the system behavior observed, i.e., the permeate flux, concentration polarization; permeate concentration and the salt rejection are predicted so that the effect of the buffering system can be analyzed. The system in Figure 1 is composed of several components, which include the wind turbine, pressure vessel, high pressure pump, RO unit and energy recovery device (ERD). In the following, sub-models of the important components of the complete system will describe starting from the wind turbine to the RO unit and energy recovery device.

\subsection{Wind Power Supply}

As the wind is the only power supply in the system, it is therefore important that the wind turbine can produce enough energy to pump water at a high pressure over varieties of wind speeds. The upper bound of the wind power production can be calculated using the turbine efficiency $\eta$ and the capacity of the pump $W_{p}$ it is connected to. For a wind turbine with $\eta=60 \%$ and taking, for example a pump with 1:4 step up connected to the wind turbine, the power, which is transmitted to the pump can be easily calculated as.

$$
W_{p}=60 W_{T}
$$

As in Karimanzira et al. [5], the power produced by a wind turbine at a given wind speed can be expressed as in the following equation.

$$
W_{T}=\frac{1}{2} \cdot \rho_{\text {air }} \cdot C_{p t} \cdot A_{\text {rotor }} \cdot V_{\text {wind }}^{3}
$$

where $W_{T}$ is the power generated in $\mathrm{kW}, \rho_{\text {air }}$ is the density of air which is 
assumed to be $1.1839 \mathrm{~kg} / \mathrm{m}^{3}, A_{\text {rotor }}$ is the area swept by the blades of the turbine in $\mathrm{m}^{2}$ and $V_{\text {wind }}$ is the wind speed in $\mathrm{m} / \mathrm{s}$ and $C_{p t}$ is the power coefficient which is a term equivalent to the efficiency of the turbine.

\subsection{Variable Speed High Pressure Water Pump}

The capacity of the pump in $\mathrm{kW}$ required to pump feed water at the standard feed flow rate of $Q_{f}$, at a standard pressure $\Delta p$ of 800 psi can be expressed as in Equation (3).

$$
W_{p}=Q_{f} \cdot \Delta p
$$

Due to the varying available power from the instantaneous variation in the wind speeds, the pump flow rates as well as the pressures vary too. Therefore, the instantaneous pump flow rates can be calculated as in [27] by using the pump affinity laws to predict the pump performance at different pump speeds. The relation between the pump power and discharge rates is given by $\frac{Q_{1}}{Q_{2}}=\left(\frac{W_{1}}{W_{2}}\right)^{1 / 3}$, which we can use in our case to find the discharge rate of the variable speed pump for the available power as,

$$
Q_{p}=Q_{\text {std }} \cdot\left(\frac{W_{p}}{W_{\text {std }}}\right)^{1 / 3}
$$

where $Q_{\text {std }}$ and $W_{\text {std }}$ are the standard feed flow rate and power above and $Q_{p}$ and $W_{p}$ is the instantaneous flow rate and power.

\subsection{Air Compressed Energy Storage Tank}

For the energy storage, we chose to use a pressure vessel, because a pressure vessel is quite common in many places and is simple to construct, economical and maintenance free. The model works as follows: An initial air pressure is used to pre-charge the energy storage tank so that as feed water is pumped into it, the inside pressure rises as air compresses. Saltwater RO desalination processes require $800-1200$ psi of pressure for reverse osmosis to occur. Therefore, in the model, water is pumped into the energy storage tank until the inside pressure reached 1000 psi. The change in volumes of the air inside the tank can be easily calculated using the ideal gas law as in equation below.

$$
P V=n R T
$$

where, $P$ denotes initial pressure of the air filled energy storage tank, $V$ is the volume of the tank. Therefore, by setting the initial air pressure $P_{0}$ and tank volume $V_{0}$, the value of the constant $n R T$ can be determined for a given temperature. From Equation (5) and now $n R T$ determined, if the volume of feed water pumped into the energy storage tank is known, the value of the new pressure inside the tank can be calculated.

\subsection{Reverse Osmosis Process Modeling}

The separation process in reverse osmosis occurs by diffusion through the 
membrane. There are two approaches proposed in literature for modeling reverse osmosis. One approach is based on the pore flow model and the other approach is based on the solution-diffusion model. In the widely accepted solution-diffusion model [28] it is assumed that the solute and the solvent dissolve in the homogeneous non porous surface layer of the membrane and the transportation occurs by diffusion under the chemical potential gradient in an uncoupled manner. The fluxes of water, $J_{w}=Q_{w} / A$, and the solute, $J_{s}$ are given by, [28] as,

$$
\begin{gathered}
J_{w}=a\left(\Delta P-\Delta \pi_{m}\right) \\
J_{s}=b\left(C_{\text {wall }}-C_{p}\right)
\end{gathered}
$$

where $\Delta P=\left(P_{b}-P_{p}\right)$ denote the difference in pressure applied across the membrane, $P_{b}$ is the pressure at the high pressure side and $P_{P}$ is the permeate side pressure. $\Delta \pi$ is the osmotic pressure difference of solute across the membrane. $C_{\text {wall }}$ is the solute concentration at the membrane surface, $C_{p}$ is the permeate side solute concentration and Constants $a$ and $b$ are the solvent and the salt permeability coefficients, respectively. Concentration polarization effects make the solute concentration at the membrane surface greater than that in the bulk solution. In the presence of concentration polarization, the steady-state water flow rate, $J_{w}$ is given by,

$$
J_{w}=k_{s} \ln \frac{C_{\text {wall }}-C_{p}}{C_{b}-C_{p}}
$$

where $C_{b}$ is bulk solute concentration of the feed side.

By substituting Equation (6) into Equation (8) to eliminate $C_{\text {wall }}$, the values of the water flux $J_{w}$ and permeate side solute concentration $C_{p}$ can be finally obtained as,

$$
\begin{gathered}
J_{w}=a\left[\Delta P-b_{\pi}\left(C_{b}-\frac{b C_{b} \exp \left(\frac{J_{w}}{k_{s}}\right)}{J_{w}+b \exp \left(\frac{J_{w}}{k_{s}}\right)}\right) \exp \left(J_{w} / k_{s}\right)\right] \\
C_{p}=C_{b}-\frac{b C_{b}}{b+J_{w} \exp \left(-\frac{J_{w}}{k_{s}}\right)}
\end{gathered}
$$

Given the values of $C_{b}, T, a, b, k_{s}, b_{\pi}$ and $\Delta P$, the water flux $J_{W}$ can be obtained from implicit nonlinear algebraic Equation (9) that can be solved numerically using the secant method. With $J_{w}$ available, the value of $C_{p}$ can then be evaluated using Equation (5).

The RO process is governed by mass and water balances given by Equation (11) and Equation (12), respectively.

$$
\begin{gathered}
Q_{f} C_{f}=Q_{p} C_{p}+Q_{r} C_{r} \\
Q_{f}=Q_{p}+Q_{r}
\end{gathered}
$$


For comparison purposes in terms of energy balance, we need to calculate the specific energy, $E$. The Specific Energy is defined as the energy in kWh required by the $\mathrm{RO}$ desalination plant to produce $\mathrm{a}^{3}$ of water. It can be expressed by Equation (13),

$$
E=\frac{\Delta P_{f} Q_{f}}{\eta Q_{p}}
$$

The salt rejection of the membrane depends solely on the output permeate and feed concentrations and can be expressed as in the following equation

$$
S R=\left(1-\frac{C_{p}}{C_{b}}\right) \cdot 100
$$

\subsection{Energy Recovery Device}

It is obvious that energy recovery is necessary in $\mathrm{RO}$ desalination process. As seen in Literature, the typical recovery ratio is around $30 \%$, and therefore, most of the seawater is rejected at a pressure which is quite high, only slightly below the applied pressure. Hence, in large RO desalination plants, energy recovery devices such as Clark pump or Pelton turbines [29] [30] are used to recover the energy and return it to the high-pressure pump. The energy of the rejected brine can be calculated using:

$$
P=Q_{b} \times P_{r} \times \eta_{t}
$$

where $P$ is the recovered energy $(\mathrm{kW}), Q_{b}$ is the brine flow rate $\left(\mathrm{m}^{3} / \mathrm{s}\right), \quad P_{r}$ is the brine pressure $(\mathrm{kPa})$, and $E_{t}$ is the turbine efficiency. $\eta_{t}$ is assumed to be 0.67 when the turbine is a reversed centrifugal pump, and $0.84-0.88$ when it is an impulse wheel turbine. With energy recovery device, the total energy requirement $E_{T}$ is given by the following equation:

$$
E_{T}=E_{h p}-E_{E R D}
$$

where $E_{h p}$ is the energy required by the variable speed high pressure pump and $E_{E R D}$ is the recovered energy.

\subsection{Membrane Fouling}

In a real RO desalination setup, both the permeate flux and the salt rejection decline due to membrane fouling, which is an avoidable phenomenon. The determination of fouling is important for scheduling maintenance and cleaning-in-place schemes to restore membrane performance. We incorporate the fouling model from [31] which takes into account the impact of fouling on both water and salt permeability in the simulation. Hence, the water and salt permeability coefficients incorporating performance decline due to fouling are described by the following equations,

$$
\begin{aligned}
& A_{w}=A_{w 0}\left(1-\theta_{1} t_{2}\right) A_{w}^{f}\left(t_{1}\right) \\
& A_{s}=A_{s 0}\left(1-\theta_{2} t_{2}\right) A_{s}^{f}\left(t_{1}\right)
\end{aligned}
$$


where $A_{w 0}$ and $A_{50}$ are the water and salt permeability coefficients without fouling, respectively, $t_{1}$ is the time since the last cleaning-in-place, $t_{2}$ is the operation time. $A_{w}^{f}\left(t_{1}\right)$ and $A_{s}^{f}\left(t_{1}\right)$ are water and salt membrane permeability decline factors, respectively.

\subsection{Simulation Model}

The sub-models were linked according to the schema in Figure 1 to build a simulation model of the complete system. The simulation program is shown in the flow chart in Figure 2. The pumping rate is calculated as a function of the wind and from the pump rate, the initial pressure vessel inside pressure, the actual pressure and the feed water flow rate for desalination can be computed. With the $\mathrm{RO}$ parameters, pressure and the feed water flow rate, the model for $\mathrm{RO}$ is run to predict the system performance in terms of permeate flow rate, specific energy, permeate concentration, etc.

The two modes of operation were configured as follows:

1) The base mode of operation was comprised of a wind turbine for energy supply, variable speed high pressure pump, the RO unit and the energy recovery device. The RO units got the feed water directly from the high pressure pump driven by the wind turbine. In this configuration, the RO unit was subjected to varying feed flow, the system was subjected to the intermittent nature of wind power, i.e., the energy buffering system was not included. In this base mode the system was made to operate continuously, as in most of the available desalination

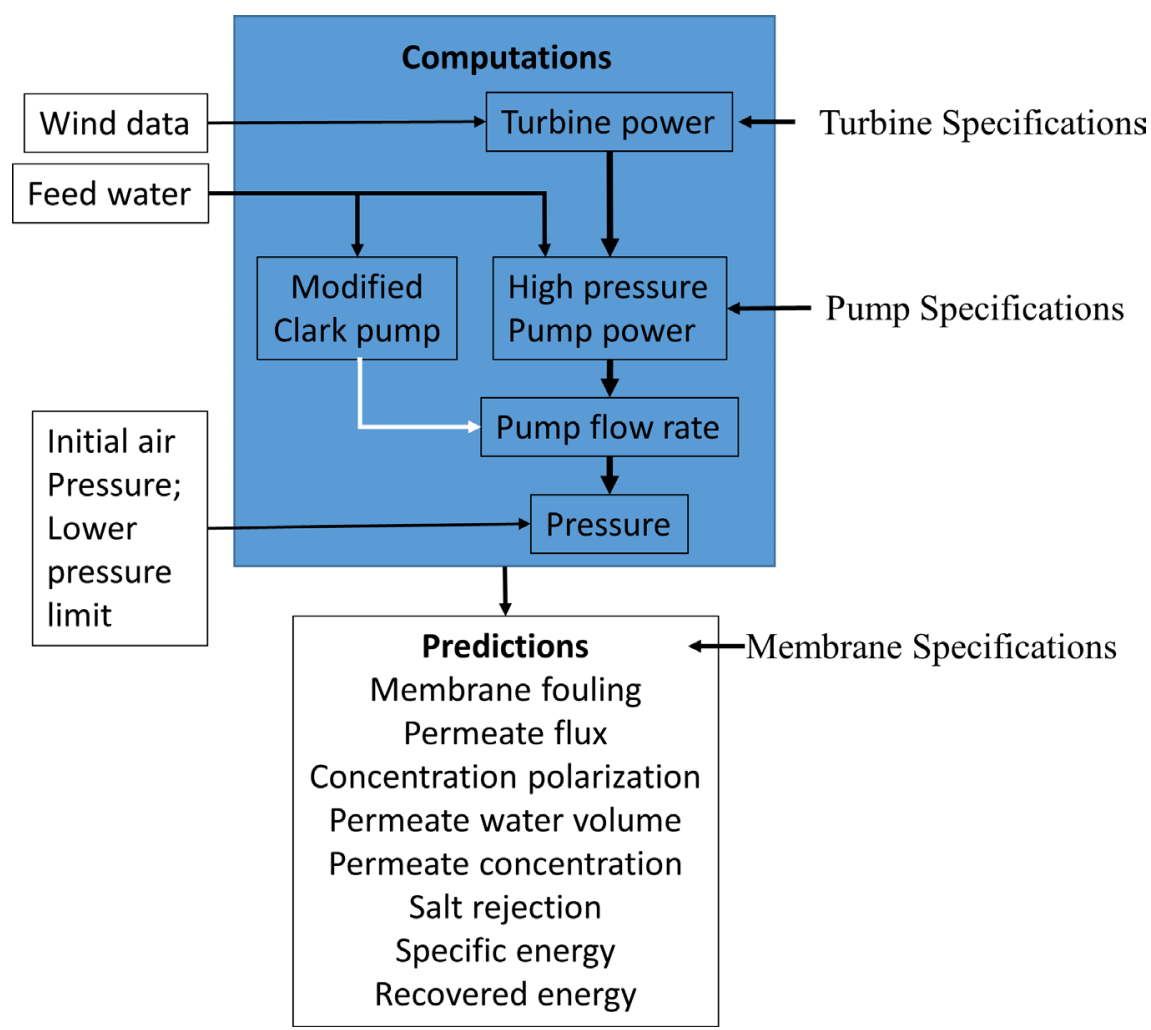

Figure 2. Chart showing the simulation program flow. 
plants. It is obvious that if the wind is at its minimum, the flow and the pressure will also be low. Assumptions were made that the system starts and stops were instantaneous. Using the ERD, recovered energy was fed back to the pump shaft.

2) In the second mode of operation, the system now included a buffering mechanism between the variable speed high pressure pump and the RO unit to store energy and dampen the power fluctuations so as to maintain constant flow rates. In this configuration, the system was run in batches as a two stage process with fill the energy storage tank and then desalination. In the fill stage, a pressure vessel pre-charged with initial air pressure was filled with feed water while the air inside is being compressed. When the pressure of the compressed air reaches the desired 1000 psi the filling of the pressure vessel was stopped and the second stage was started. Now, in the second stage of the batch process, the feed water which is pressurized in the pressure vessel was released into the RO unit in a controlled manner. Using these two stages guarantees the separation process by the membrane is isolated from the intermittent nature of the wind power. When the pressure in the pressure vessel drops to a certain level, the filling process will be started again. Operating in the batch mode like this gives better control over the system and at the same time helps in prolonging the life of the membrane, due to the fact that it is no longer exposed to the fluctuations in the feed flow rates as in the base mode. The obvious downside of the mode of operation compared to the continuously operated system in the base mode is that the RO unit is on standby during the filling phase. Again, using the ERD as in the base mode, the recovered energy was fed back to the pump shaft.

\subsection{Optimization of the Storage Mechanism}

The parameters of the pressure vessel such as the storage volume, the initial pressure (iP), lower pressure limit (IPI) have got big influence on the behavior of the system towards the numbers of cycles for desalination, permeate flow rate and concentration and also the energy demanded by the pump. Therefore, it was necessary to adapt the initial pressure and the lower pressure limit to the wind pattern to produce the best results.

We formulated an optimization problem as follows. The main aim is to produce maximum amount of the permeate volumetric flow rate $Q_{p}$ and fulfill the permeate concentration $C_{p, d}$. The control variables are the initial pressure (iP), lower pressure limit (IPI) For this given RO system configuration with pressure vessel, the objective function is given by Equation (19).

$$
\max _{i P, I P l}\left(J=Q_{p}\right)
$$

The optimization problem of the RO system is constrained by the system Equations (1)-(14) and the required permeate concentration.

$$
C_{p} \leq C_{p, d}=500 \mathrm{mg} / \mathrm{L}
$$

There are several bounds governing the system. The bounds for the initial air pressure and the lower pressure limit are as follows: 


$$
\begin{array}{r}
670 \leq i P \leq 800 \mathrm{psi} \\
670 \leq l P l \leq 980 \mathrm{psi}
\end{array}
$$

The other influencing parameters such as the tank volume of the pressure vessel and number of membrane elements were fixed.

The problem can be solved by any nonlinear SQP solver such as fmincon from Matlab ${ }^{\circledR}$ or IPOPT from COIN-OR.

\section{Case Study}

A hypothetical desalination plant was setup and parameterized using specifications from products available on the market as follows.

\subsection{Components Parameterization}

The parameters of the wind turbine were set according to the power requirements of the pump which is given by Equation (3). From Equation (3), the power $(\mathrm{kW})$ to pump feed water at standard feed flow rate of $Q_{f}$ of $300 \mathrm{~m}^{3} / \mathrm{d}$ at the given standard pressure $(\Delta p)$ of $800 \mathrm{psi}$ is approx. $18 \mathrm{~kW}$. From this requirement value of the pump power and the pump efficiency of 0.6 , the required capacity of the wind turbine can be calculated using Equation (4) to roughly $38 \mathrm{~kW}$. Hence, a wind turbine with rated power of $50 \mathrm{~kW}$ was selected.

The volume of the pressure vessel is also a very important parameter, as it decides how fast or slow the pressure inside builds. After several tests on the effect of the volume on the water production we chose a pressure vessel with a capacity of $18 \mathrm{~m}^{3}$ as the storage mechanism.

For the RO unit the most important component is the membrane and this had to be parameterized to get realistic tests. The Filmtec SW30HR-320 Seawater is one of the common used membrane for seawater desalination, so we parameterize our model with its specifications which are shown in Table 1.

\subsection{Feed Water and Wind Data}

To simulate seawater, the concentration of the feed water was set to $32,000 \mathrm{mg} / \mathrm{L}$.

Table 1. Product specifications of the SW30HR-320 Membrane.

\begin{tabular}{ccc}
\hline Parameter & Value & Unit \\
Feed Spacer & 34 & $\mathrm{mil}$ \\
Element diameter & 0.201 & $\mathrm{~m}$ \\
Length & 1.016 & $\mathrm{~m}$ \\
Permeate tube diameter & 0.029 & $\mathrm{~m}^{2}$ \\
Active Area & 320 & $\mathrm{kPa}^{2}(\mathrm{psig})$ \\
Maximum operating pressure & $6900(1200)$ & $\mathrm{m}^{3} / \mathrm{d}$ \\
Permeate flow rate & 23 & $\%$ \\
Minimum salt rejection & 99.6 & $\%$ \\
\hline
\end{tabular}


As the system is driven by wind power, the main input to the system is the wind speed pattern. For the wind data input, we used data recorded at our institute. $24 \mathrm{hr}$ data was selected from 4 different days in different times of the year such that a wide range of wind regimes are covered for the system tests. The wind regimes 1 - 4 with the mean of $6.98 \mathrm{~m} / \mathrm{s}, 4.78 \mathrm{~m} / \mathrm{s}, 4.21 \mathrm{~m} / \mathrm{s}$, and $1.60 \mathrm{~m} / \mathrm{s}$, respectively, are shown in Figures 3(1)-(4). Furthermore, for better comparison, the system was tested with constant wind speed of $10 \mathrm{~m} / \mathrm{s}, 6.6 \mathrm{~m} / \mathrm{s}, 5 \mathrm{~m} / \mathrm{s}$ and 2 $\mathrm{m} / \mathrm{s}$.

\section{Results and Discussions}

The results of the tests for the different scenarios will be shown and discussed in this section. The system was run in the two modes one after the other using the different wind patterns as inputs and the results of the predictions were recorded.

\subsection{Base Case without Energy Storage}

Table 2 shows the results of the simulation of the base mode (system without storage). The performance measures include, the permeate flow rate, specific energy, permeate concentration, etc. The first steady wind speed scenario of 10.1
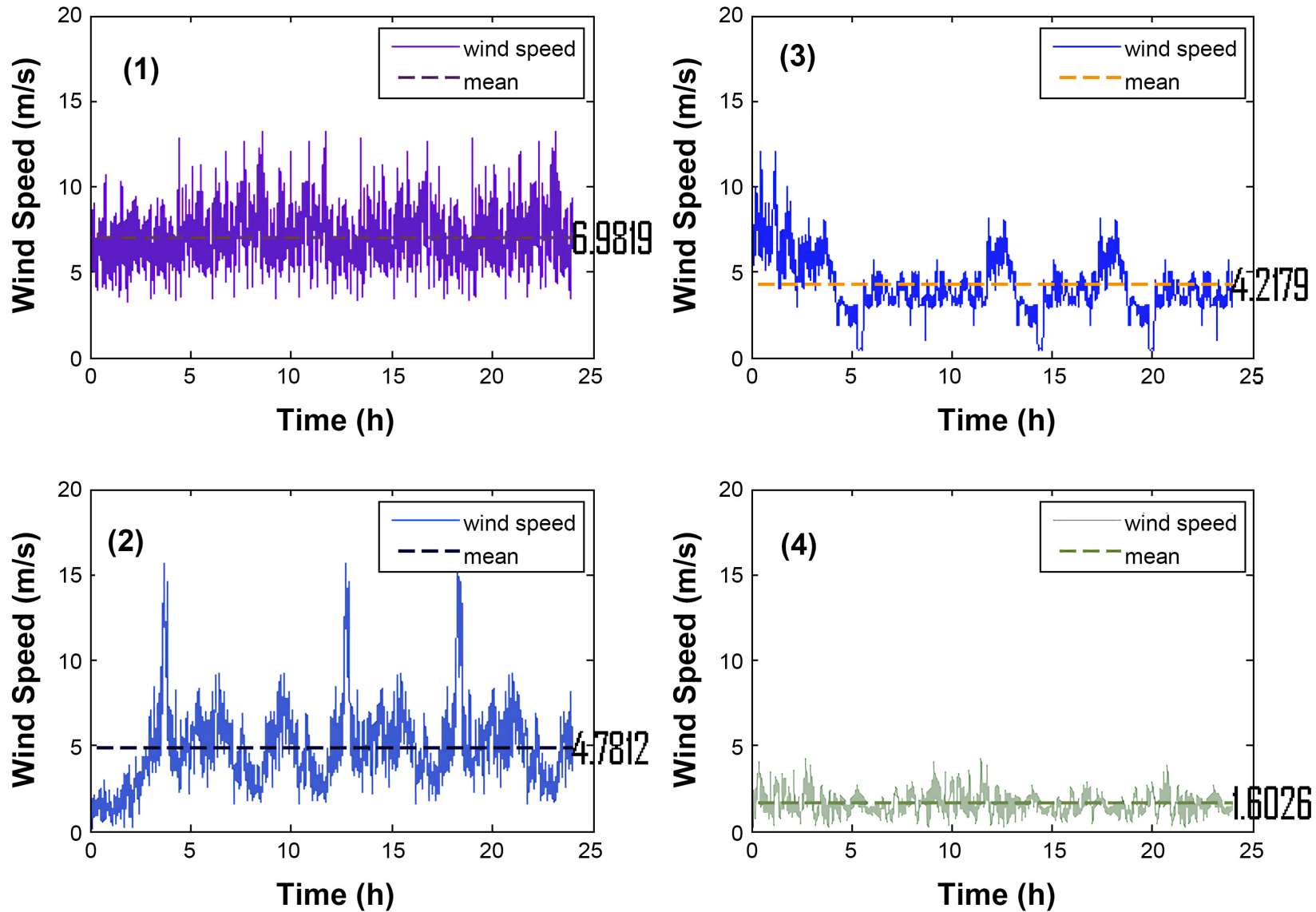

Figure 3. Wind scenarios 1 - 4 with the mean of $6.98 \mathrm{~m} / \mathrm{s}, 4.78 \mathrm{~m} / \mathrm{s}, 4.21 \mathrm{~m} / \mathrm{s}$, and $1.60 \mathrm{~m} / \mathrm{s}$, respectively. 
Table 2. Results of the steady and different wind pattern for water production.

\begin{tabular}{|c|c|c|c|c|c|c|}
\hline \multirow[b]{2}{*}{ Quality criteria } & \multicolumn{2}{|c|}{ Steady wind } & \multicolumn{4}{|c|}{ Wind patterns } \\
\hline & $10.1 \mathrm{~m} / \mathrm{s}$ & $<6.0 \mathrm{~m} / \mathrm{s}$ & $1-$ avg. $6.98 \mathrm{~m} / \mathrm{s}$ & 2 - avg. $4.78 \mathrm{~m} / \mathrm{s}$ & $3-$ avg. $4.21 \mathrm{~m} / \mathrm{s}$ & $4-$ avg. $1.60 \mathrm{~m} / \mathrm{s}$ \\
\hline Total Permeate Volume [L] & $73,283.04$ & & $13,996.60$ & 4762.82 & 4761.40 & \\
\hline Design Permeate flowrate $\left[\mathrm{m}^{3} / \mathrm{d}\right]$ & 185.461 & & 38.36 & 13.141 & 13.03 & \\
\hline Specific Energy $\left[\mathrm{KWh} / \mathrm{m}^{3}\right]$ & 5.578 & & 9.54 & 12.96 & 12.5 & \\
\hline Permeate water quality $[\mathrm{mg} / \mathrm{L}]$ & 777.43 & & 1005.93 & 1038.5 & 897.65 & \\
\hline Rejection & 97.57 & System fails & 96.85 & 96.75 & 97.19 & System fails \\
\hline Recovery 1 & 5.48 & & 1.91 & 0.94 & 1.08 & \\
\hline Recovery 2 & 5.47 & & 1.80 & 0.88 & 1.01 & \\
\hline Recovery 3 & 5.38 & & 1.69 & 0.81 & 0.94 & \\
\hline Total Recovery & 83.90 & & 19.24 & 8.93 & 10.32 & \\
\hline
\end{tabular}

$\mathrm{m} / \mathrm{s}$, made the pump produce enough pressure of 985 psi resulting in high permeate flux of $7 \mathrm{~m}^{3} /$ day. But, further examination with steady winds lower than 6 $\mathrm{m} / \mathrm{s}$ show that the high pressure pump could not develop enough pressures as required by the reverse osmosis process to occur. Therefore, the whole system failed.

From these steady wind studies, it can be concluded that the winds driving the desalination plant should be relatively high for the desalination process to take place. Steady winds are desirable, but the reality is different, a high pressure pump supplied by variable energy source cannot produce constant feed flows, hence, the permeate flows are expected to be lower for the different real wind regimes as the results in Table 2 show.

From the wind patterns selected for the experiments, Wind pattern 1 had the best average wind speed with $6.98 \mathrm{~m} / \mathrm{s}$, therefore, it was the one which produced the highest quantity and quality of permeate as can be seen in Table 2 . The wind pattern with the minimum average of $1.60 \mathrm{~m} / \mathrm{s}$ in wind speed produced the worst results as it fails to produce an water as the wind speed was not enough to drive the variable speed high pressure pump to develop enough pressure for the RO unit. All the water production rate of the real wind patterns were always lower than that of the steady wind conditions, which suggest that constancy is required and this calls for energy buffering as in our second mode of operation.

As expected, the values of the permeate concentration are lower for the wind pattern with high average wind speed and higher as the wind speed average gets lower. This behavior easily explains with solution-diffusion principles. The quantity of salt passing through the membrane and landing in the permeate flux is inversely proportional to the water quantity passing through the membrane. As lower wind speeds cause less pressure and produce lower permeate quantity thus increasing the concentrations the permeate.

Figures 4(a)-(d) show the results of simulating wind-powered RO desalination without storage based on the example of wind pattern 2 . In (a), the wind 

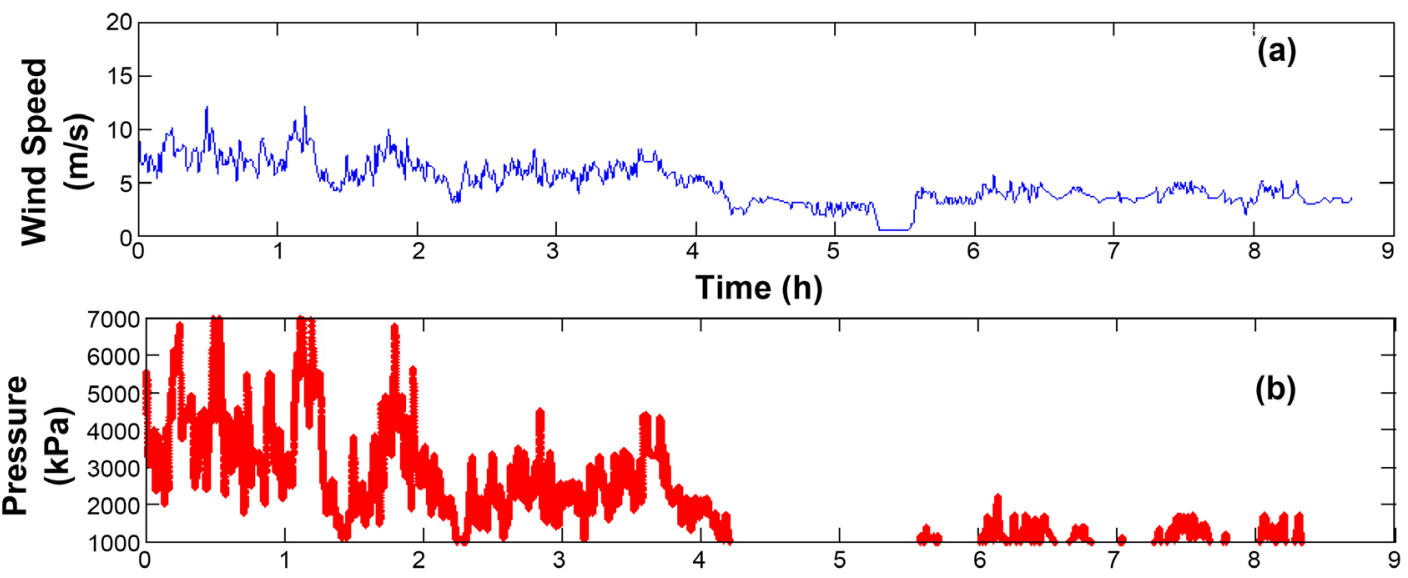

Time (h)
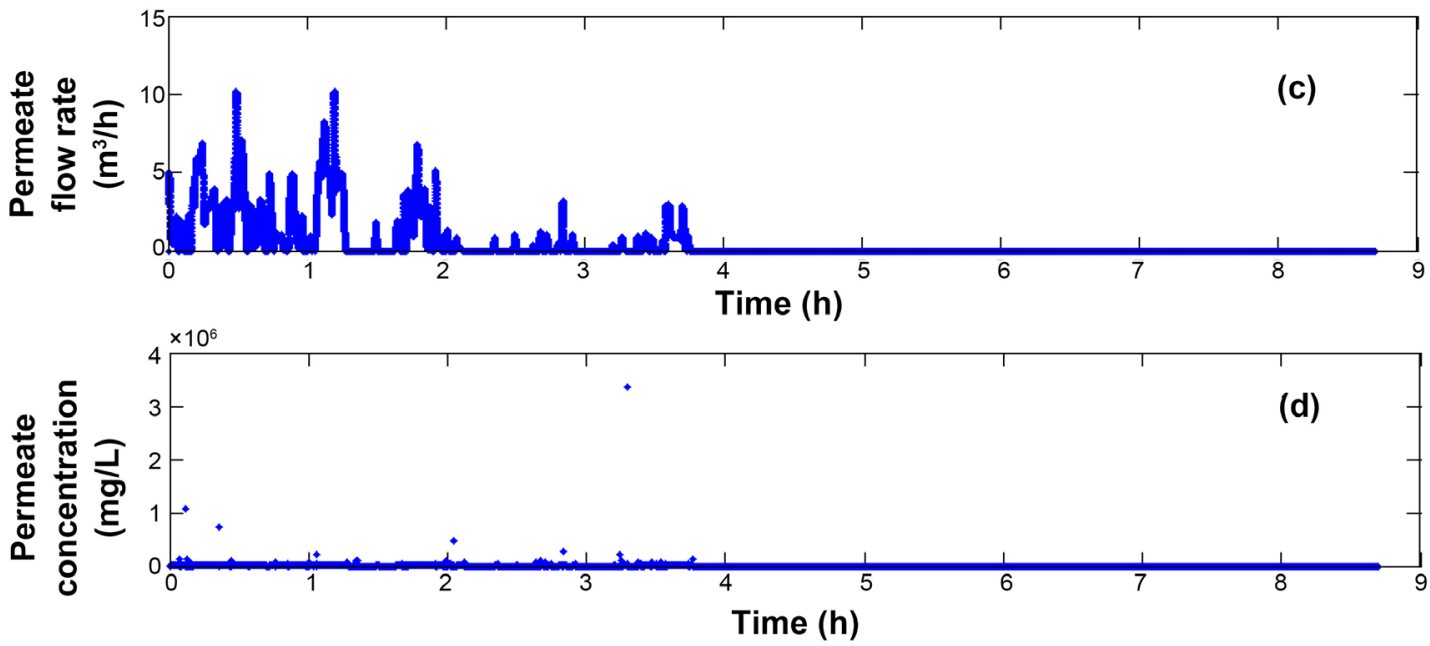

Figure 4. Results of simulating wind-powered RO desalination without storage. (a) Wind character-istics, (b) inside pressure of the pressure vessel (c) permeate flow rate (d) permeate salt concentration.

variation between 0 and 14 can be seen. Furthermore, in Figure 4(b) it can be seen that the intermittent character of the wind is directly propagated to the high pressure pump and the permeate quantity (Figure $4(\mathrm{c})$ ) and quality (Figure $4(d))$ are produced accordingly.

\subsection{System with Energy Storage}

In the second mode of operation, the results of the two different stages of the batch process will be discussed, starting with the filling of the pressure vessel. Using the results of the wind pattern 2 illustrated in Figures 5(a)-(d), the behavior of pressure vessel previously described in the methodology section can be clearly seen. The pressure vessel is filled at the beginning and has a pressure of $600 \mathrm{psi}(4134 \mathrm{kPa})$. When the feed water is being filled in by the variable speed high pressure pup, the air in the tank is compressed until 1000 psi $(6900 \mathrm{kPa})$. This describes the first stage. Upon reaching this maximum pressure limit, the pressure in the vessel begins to fall again. It is now due to the stage, where the feed water in the pressure vessel is released into the $\mathrm{RO}$ unit for desalination. 

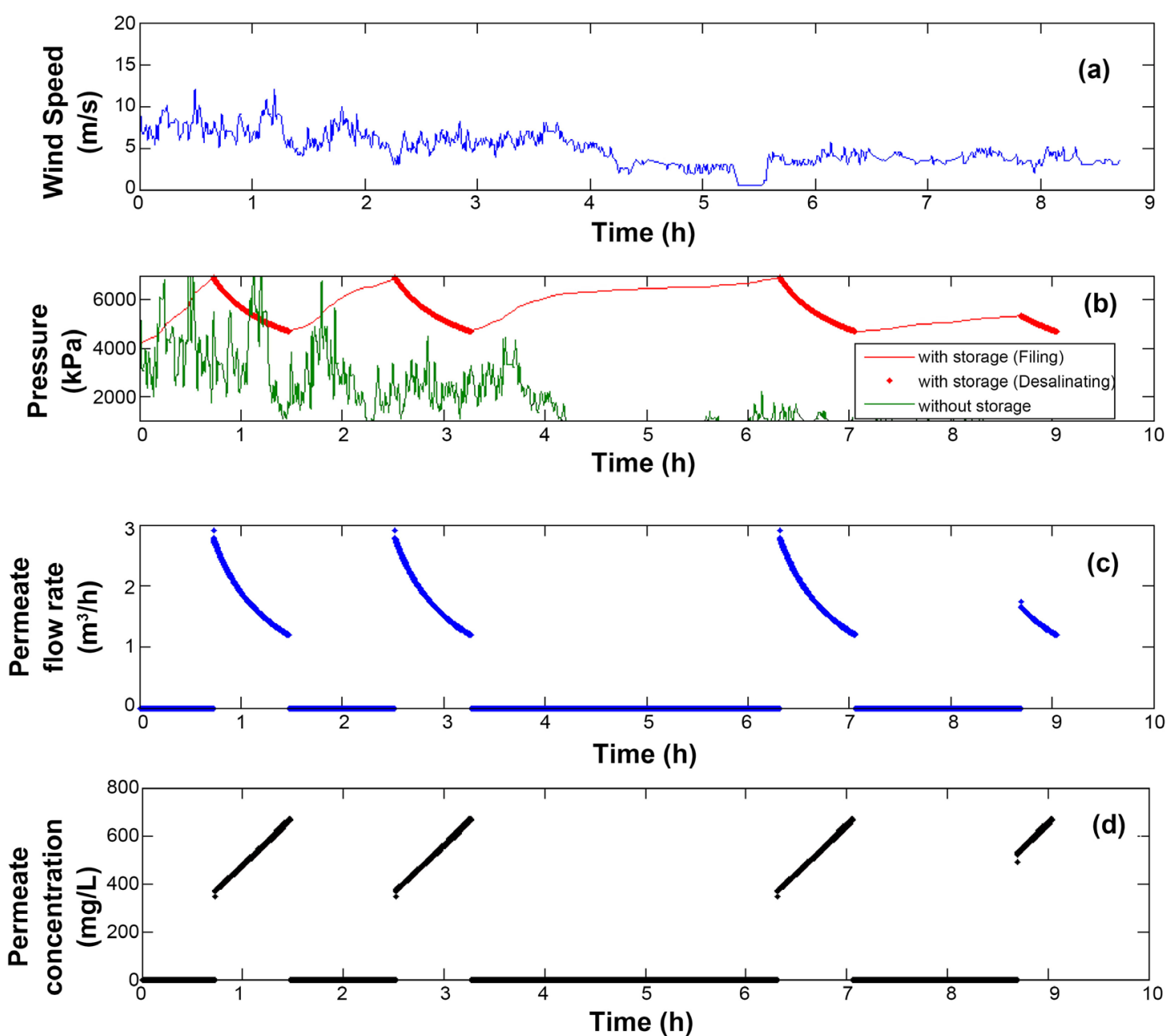

Figure 5. Operation of the system in the second mode in batch mode for wind pattern 2 as an example. (a) inside pressure of the pressure vessel (b) permeate flow rate (c) permeate salt concentration.

After this, when the pressure vessel inside pressure reaches the set lower limit of $680 \mathrm{psi}$, the reverse osmosis process stops and stage one starts again according to the available wind power. In Figure 5(b), it can be seen that the first stage did not complete to the upper limit of $1000 \mathrm{psi}$ in the last cycle, the filling of the pressure vessel stopped due to shortage of wind power, so the second stage started again with the available pressure inside the vessel. There are several factors that determine the number of cycles run in the batch process such as the vessel capacity, the initial air pressure, the maximum and minimum pressure limit so as the available wind power.

The same behavior as the pressure in the vessel is observed for the predictive variables. In Figure 5(b), it can be seen the permeate flow rate is greater than zero, when the pressure vessel is releasing feed water. The discontinuities in the graphs of the permeate flux and concentrate indicate that the $\mathrm{RO}$ unit is not in use during the first stage of the batch process. As discussed previously in the base case, a high quantity of water is produced when the pressure is high and with the decrease of pressure when the pressure vessel is emptying it decreases 
too as can be seen in Figure 5(c). The contrary behavior can be seen for the permeate concentration, it increases as the pressure in the pressure vessel decreases (Figure 5(d)). For comparison, another example with wind pattern 3 is given in Figures 6(a)-(d). The behavior is the same for the all the performance measure, but due to the difference in the wind quantity (average of $4.72 \mathrm{~m} / \mathrm{s}$ compared to $6.98 \mathrm{~m} / \mathrm{s}$ ), the number of cycles is less and all the values are lower.

Table 3 shows all the performance results for the 4 wind scenarios. The wind pattern 1 with the highest wind average is the one which had the highest recovery rate and produced the highest amount of water in the given time. Because of this high wind speed average it takes shorter to the pressure vessel to fill up and pressurize. Therefore, it had the highest number of cycle too. The lower the average the wind speed is, the less number of cycles can be realized and the less water will be produced as can be seen in Table 3 for the wind pattern 2, 3 and 4 . On one hand, as can be seen in Table 3, the average filling time for the wind pattern 4 was 502.71 minutes compared to 48.31 minutes of wind pattern 1 . On
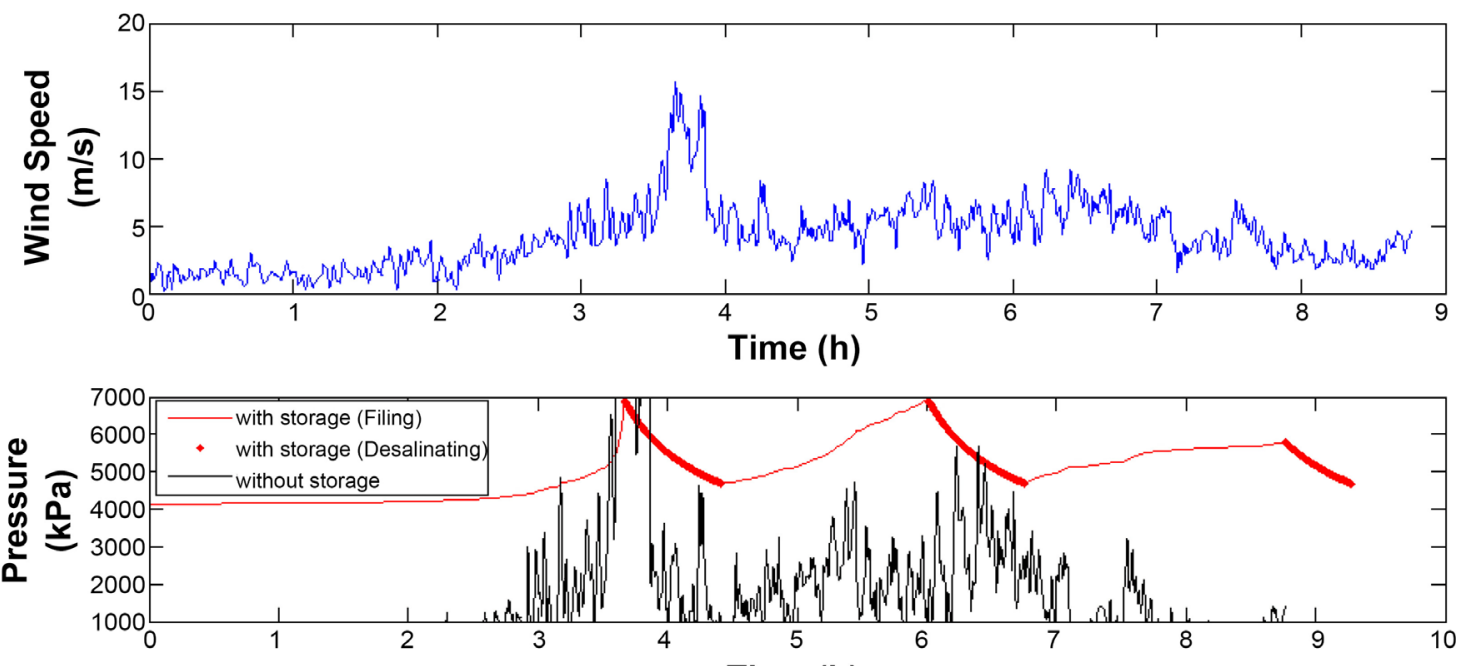

Time (h)

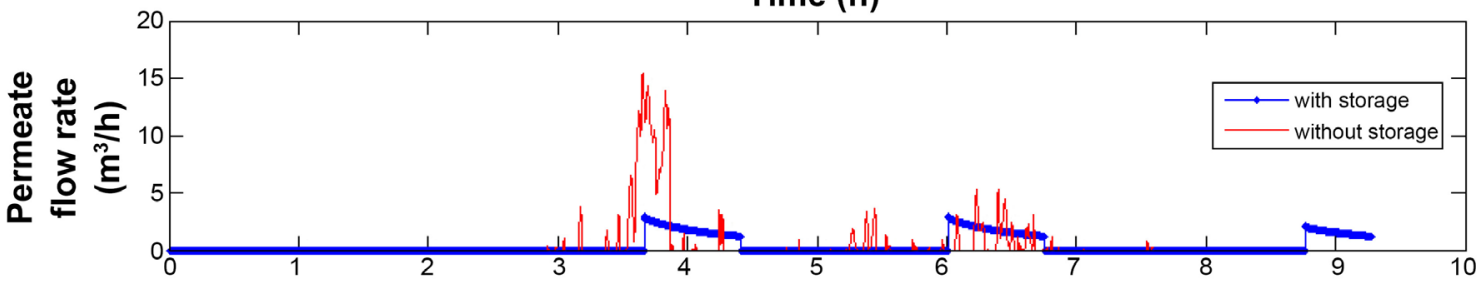

Time (h)

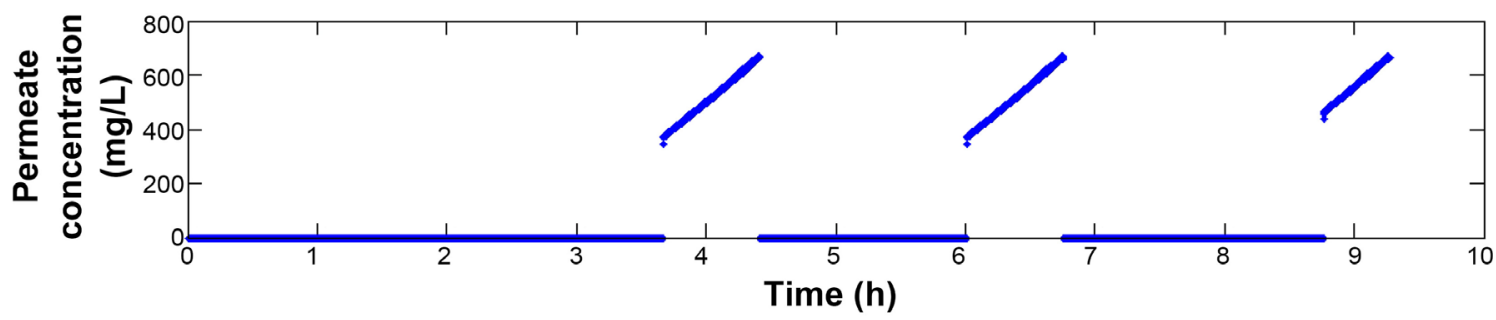

Figure 6. Operation of the system in the second mode in batch mode for wind pattern 3 as an example. (a) Wind pattern 3, (b) inside pressure of the pressure vessel (b) permeate flow rate (c) permeate salt concentration. 
Table 3. Performance of the system with the pressure vessel for the different wind scenarios. Higher wind average speed is important to increase the number of productions cycles and hence water production.

\begin{tabular}{ccccc}
\hline & \multicolumn{5}{c}{ Wind pattern } \\
\hline Quality criteria & $1(10 \mathrm{hrs})$ & $2(10 \mathrm{hrs})$ & $3(10 \mathrm{hrs})$ & $4(20 \mathrm{hrs})$ \\
\hline Permeate water quality $[\mathrm{mg} / \mathrm{L}]$ & 496.60 & 507.06 & 509.94 & 511.71 \\
Total Permeate Volume $[\mathrm{L}]$ & 7951.35 & 4459.11 & 3419.87 & 1477.50 \\
Permeate flow rate $\left[\mathrm{m}^{3} / \mathrm{d}\right]$ & 20.518 & 11.83 & 8.85 & 2.01 \\
Specific Energy $\left[\mathrm{KWh} / \mathrm{m}^{3}\right]$ & 16.80 & 13.85 & 17.41 & 11.06 \\
Number of cycles & 6 & 4 & 3 & 2 \\
Rejection $\left[\mathrm{KWh} / \mathrm{m}^{3}\right]$ & 98.44 & 98.41 & 98.406 & 98.40 \\
Avg. filling time $[\mathrm{min}]$ & 48.31 & 96.94 & 145.57 & 502.71 \\
Avg. Desalination time $[\mathrm{min}]$ & 44.66 & 38.69 & 39.87 & 25.98 \\
\hline
\end{tabular}

the other hand, the desalination time is almost half for the wind pattern 4 . Compare to the base case (without storage) which completely failed with wind pattern 4, the system with storage works fine through energy accumulation and produces some water.

\subsection{System with Energy Storage and Optimization}

The previously discussed simulations were conducted with parameters of the pressure vessel (initial are pressure, lower pressure limit), which were obtained from experience. It was worth studying what brings the optimization of the parameters. Therefore, for the second mode of operation with the storage mechanism, we run optimization of the system to find the best initial air pressure (iP) and the lower pressure limit $I P I$ for the four wind scenarios. The results from the optimization are shown in Table 4.

The obtained optimization results are in alignment with the results from experiments. The optimization algorithm has to make compromises as follows:

- On one hand, increasing the initial air pressures will increase the permeate flow rates, but high initial pressure means more energy is required by the pump to pump feed water. On the other hand, the pressure drop in the pressure vessel during the desalination phase is slow the higher the initial air pressure is, what is desirable.

- The lower pressure limit and the initial pressure have contrary effect on the permeate flow rate and the permeate concentration, i.e., the initial pressure inside the pressure vessel governs the permeate flow rate but does not influence the permeate concentration, whereas the lower pressure limit has the opposite effect. It affects the permeate concentration and does not affect the permeate flow rate.

- The lowest salt concentrations are obtained if the lower limit is quite high, while at about $670 \mathrm{psi}$ the concentrations are around $500 \mathrm{mg} / \mathrm{L}$. If the lower 
pressure limit is reduced further, the salt concentrations will be higher than $500 \mathrm{mg} / \mathrm{L}$.

- It is also clear that, if the lower pressure limits are set too low the will always be more water remaining unused in the pressure vessel and decreasing the lower pressure limit and setting the initial air high, increases the unused water.

Comparison results in Table 5 of the optimized and suboptimal system based on the worst case wind scenario 4 show what the optimization can bring. The optimization results show that all the constraints such as the required maximum permeate concentration are fulfilled, but the system produces much higher permeate flow rate, better specific energy and higher average desalination time of 46.57 minutes compared to 25.98 minutes. Figures 7(b)-(d) shows as an example the comparison between optimized and suboptimal systems based on the worst case wind scenario 4 . It can be seen in Figures 7(b)-(d), for the optimized system were two versions, one where the constraint on the permeate concentration was set as hard constraints and the other one where it was set as soft constraints. These two were compared to the suboptimal system and the system without storage. Due to the limitation of the permeate concentration $\left(C_{p}<500 \mathrm{mg} / \mathrm{L}\right)$ this system terminates its desalination cycle earlier because low pressure in the pressure vessel causes the concentration to rise and therefore, the pressure needs to be increased again by starting a new fill cycle.

Table 4. Optimal parameters found by the optimization for the different wind patterns.

\begin{tabular}{ccc}
\hline Wind pattern & Initial air pressure $(i P)$ & Lower pressure limit $I P I$ \\
\hline 1-with avg $6.98 \mathrm{~m} / \mathrm{s}$ wind speed & 600 & 670 \\
2-with avg $4.78 \mathrm{~m} / \mathrm{s}$ wind speed & 722 & 680 \\
3-with avg $4.21 \mathrm{~m} / \mathrm{s}$ wind speed & 756 & 720 \\
4-with avg $1.60 \mathrm{~m} / \mathrm{s}$ wind speed & 800 & 800 \\
\hline
\end{tabular}

Table 5. Comparison of the optimal and suboptimal systems based on the worst-case wind scenario.

\begin{tabular}{|c|c|c|}
\hline Quality criteria & 4 & 4-optimized \\
\hline Permeate water quality $[\mathrm{mg} / \mathrm{L}]$ & 511.71 & 434.27 \\
\hline Total Permeate Volume [L] & 1477.50 & 2579.88 \\
\hline Permeate flow rate $\left[\mathrm{m}^{3} / \mathrm{d}\right]$ & 2.01 & 3.43 \\
\hline Specific Energy $\left[\mathrm{KWh} / \mathrm{m}^{3}\right]$ & 11.06 & 6.34 \\
\hline Number of cycles & 2 & 2 \\
\hline Rejection $\left[\mathrm{KWh} / \mathrm{m}^{3}\right]$ & 98.40 & 98.64 \\
\hline Avg. filling time [min] & 502.71 & 495.26 \\
\hline Avg. Desalination time [min] & 25.98 & 46.57 \\
\hline
\end{tabular}



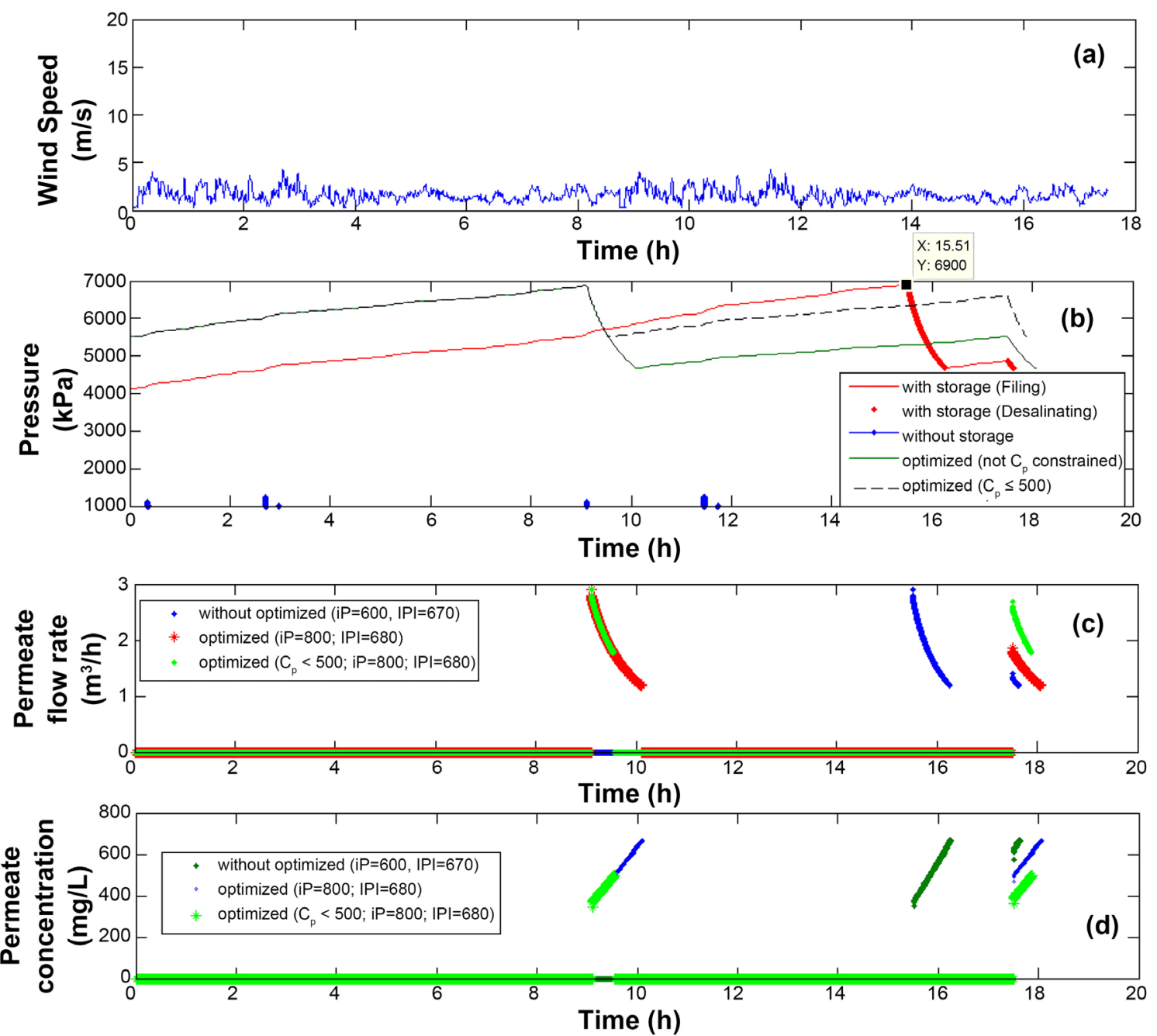

Figure 7. Comparison between optimized and suboptimal systems. (a) Wind pattern 4, (b) inside pressure of the pressure vessel $(c)$ permeate flow rate $(d)$ permeate salt concentration.

\subsection{System with Energy Recovery}

Some test were conducted with respect to the energy recovery. Selected result for the wind pattern 4 is shown in Table 6 . It can be seen that the specific energy for the system improved from $6.34 \mathrm{kWh} / \mathrm{m}^{3}$ to $4.97 \mathrm{kWh} / \mathrm{m}^{3}$. Besides that all other values such as the average permeate water quality, rejection, water production etc. improved as well. It can be seen in Figure $8(\mathrm{~b})$ that the desalination stage was longer with energy recovery with an average desalination time of $56.68 \mathrm{mi}$ nutes compared to 46.57 minutes without ERD. Figure 8(c) \& Figure 8(d) show a similar improvement in the permeate flow rate and quality.

\section{Conclusions}

The main goal of this work was to show the feasibility of using an intermittent energy source such as wind with or without storage to drive a desalination plant. A simulation system for a wind-powered desalination plant with energy recovery was presented. The advantages of using wind as the source of energy compared 
Table 6. System performance of the RO process with/without energy recovery device (ERD).

\begin{tabular}{ccc}
\hline Criteria & Without ERD & With ERD \\
\hline Permeate water quality $[\mathrm{mg} / \mathrm{L}]$ & 521.64 & 505.16 \\
Total Permeate Volume $[\mathrm{L}]$ & 2579.88 & 3284.02 \\
Permeate flow rate $\left[\mathrm{m}^{3} / \mathrm{d}\right]$ & 3.43 & 4.28 \\
Specific Energy $\left[\mathrm{KWh} / \mathrm{m}^{3}\right]$ & 6.34 & 4.97 \\
Number of cycles & 2 & 2 \\
Rejection $\left[\mathrm{KWh} / \mathrm{m}^{3}\right]$ & 98.37 & 98.42 \\
Avg. filling time $[\mathrm{min}]$ & 495.26 & 495.27 \\
Avg. Desalination time $[\mathrm{min}]$ & 46.57 & 56.68 \\
\hline
\end{tabular}

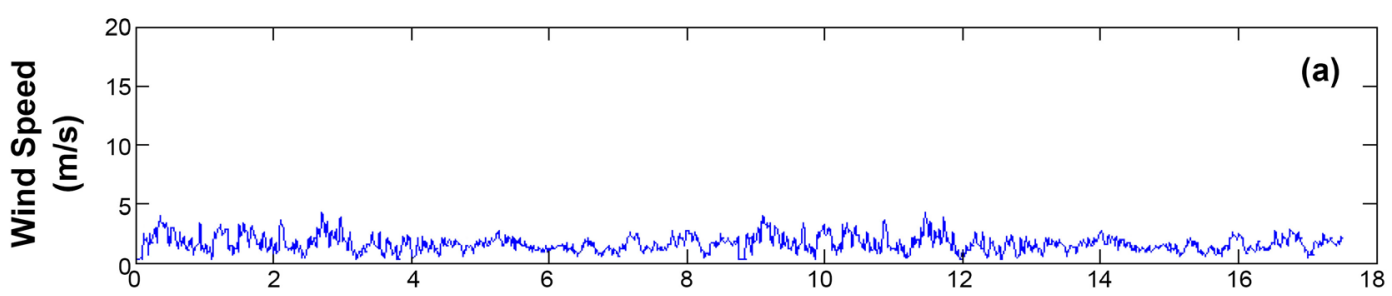

Time (h)

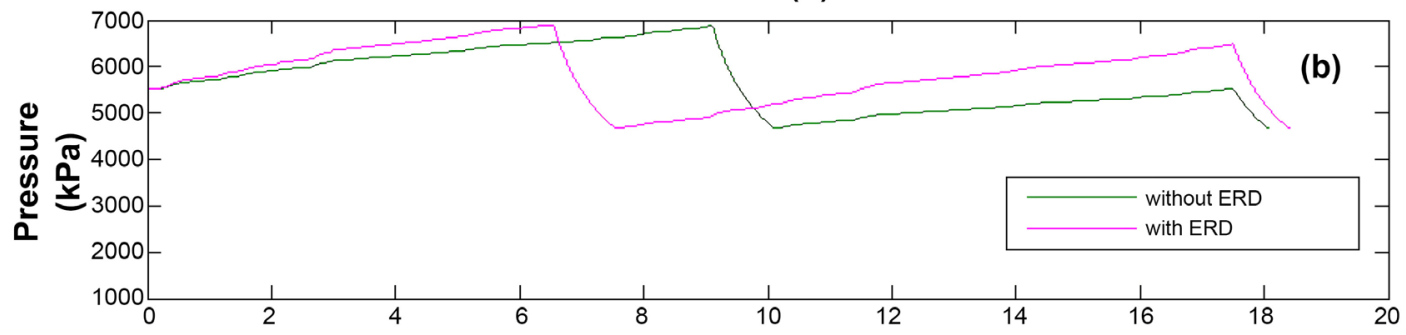

Time (h)
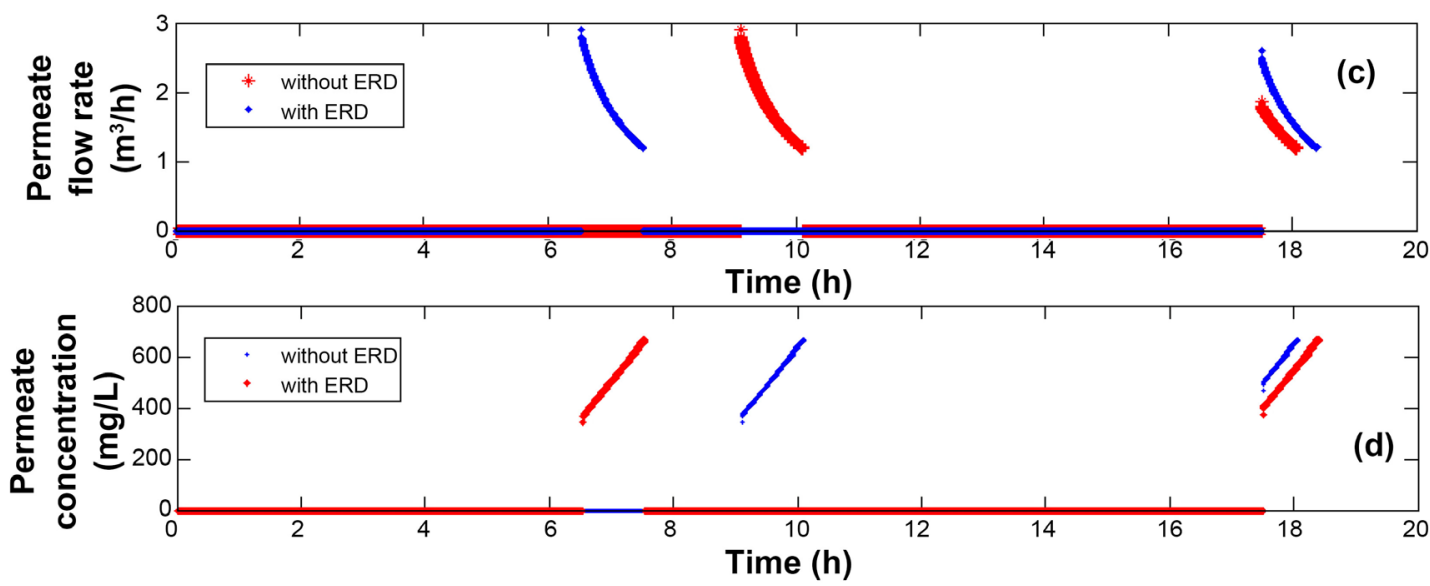

Figure 8. Comparison of the system performance with and without ERD, (a) wind pattern, (b) pressure development in the pressure vessel, (c) permeate flow rate and (d) the permeate concentration.

to other renewable sources for seawater desalination have been explained. The model can be used for investigation on the effect of using energy storage system as buffer for the intermittent energy sources on the performance of the system 
measured by permeate flux quality and salt rejection. The system can be operated in two modes. In the base mode, no buffering of energy is available and it runs continuously. The variations in wind speed are passed directly to the RO Unit and can practically cause damages to the membrane. In the second mode of operation, a storage mechanism in form of a pressure vessel is included in the system. The second mode of operation runs in batch mode in two-stage, whereby in the first stage, the pressure vessel is filled with water until a given maximum limit and then the second phase is started in which the feed water from the pressure vessel is released into the $\mathrm{RO}$ unit in a controlled manner. In this mode, the RO unit is practically isolated from the fluctuations in the feed water flow rate caused by the variations in the wind pattern. During the filling of the pressure vessel, the RO unit is not in operation and cleaning-in-place can take place if necessary. The performance of the two systems was compared under different wind scenarios and the results were given. The results show that the storage mechanism makes the system feasible and improves the performance of the system, especially when the variations of wind are large. Therefore, the main conclusion is that including a buffering mechanism between the pump and the RO Unit makes the system more productive.

The outlook is to run the system with at least two pressure vessels with optimal scheduling for filling and desalination stages. Furthermore, a demonstration plant is being built so that the results can be confirmed on a real plant.

\section{Acknowledgements}

This work was conducted during the WASTEC-Project. We, therefore, thank the Fraunhofer Gesellschaft for sponsoring the ICON-Project "WASTEC".

\section{Conflicts of Interest}

The authors declare that there is no conflict of interest.

\section{References}

[1] Li, D. and Wang, H.T. (2010) Recent Developments in Reverse Osmosis Desalination Membranes. Journal of Materials Chemistry, 20, 4551-4566. https://doi.org/10.1039/b924553g

[2] Zarzo, D. and Prats, D. (2018) Desalination and Energy Consumption. What Can We Expect in the Near Future? Desalination, 427, 1-9. https://doi.org/10.1016/j.desal.2017.10.046

[3] El-Ghonemy, A. (2012) RETRACTED: Waste Energy Recovery in Seawater Reverse Osmosis Desalination Plants. Part 2: Case Study. Renewable and Sustainable Energy Reviews, 16, 4016-4028. https://doi.org/10.1016/j.rser.2012.03.057

[4] Feo-García J., Ruiz-García, A., Ruiz-Saavedra, E. and Melian-Martel., N. (2016) Energy Consumption Assessment of $4,000 \mathrm{~m}^{3} / \mathrm{d}$ SWRO Desalination Plants. Desalination and Water Treatment, 57, 23019-23023. https://doi.org/10.1080/19443994.2015.1106095

[5] Karimanzira, D. and Rauschenbach, T. (2018) Optimal Utilization of Renewable Energy in Aquaponic Systems. Energy and Power Engineering, 10, 279-300. 
https://doi.org/10.4236/epe.2018.106018

[6] Kalogirou, S.A. (2005) Seawater Desalination Using Renewable Energy Sources. Progress in Energy and Combustion Science, 31, 242-281. https://doi.org/10.1016/j.pecs.2005.03.001

[7] Gilau, A.M. and Small, M.J. (2008) Designing Cost-Effective Seawater Reverse Osmosis System under Optimal Energy Options. Renewable Energy, 33, 617-630. https://doi.org/10.1016/j.renene.2007.03.019

[8] Koschikowski, J. (2011) Water Desalination: When and Where Will It Make Sense, Presentation at the 2011 Annual Meeting of the American Association for the Advancement of Science, Fraunhofer Institute for Solar Energy Systems (ISE). http://ec.europa.eu/dgs/jrc/downloads/jrc aaas2011 energy water koschikowski.p df

[9] Caldera, U., Bogdanov, D. and Breyer, C. (2016) Local Cost of Seawater RO Desalination Based on Solar PV and Wind Energy: A Global Estimate. Desalination, 385, 207-216. https://doi.org/10.1016/j.desal.2016.02.004

[10] Ganora, D., Dorati, C., Huld, T.A. and Pistochi, A. (2019) An Assessment of Energy Storage Options for Large-Scale PV-RO Desalination in the Extended Mediterranean Region. Scientific Reports, 9, Article No. 16234. https://doi.org/10.1038/s41598-019-52582-y

[11] Esmaeilion, F. (2020) Hybrid Renewable Energy Systems for Desalination. Applied Water Science, 10, Article No. 84. https://doi.org/10.1007/s13201-020-1168-5

[12] Al-Nory, M. and El-Beltagy M. (2014) An Energy Management Approach for Renewable Energy Integration with Power Generation and Water Desalination. Renewable Energy, 72, 377-385. https://doi.org/10.1016/j.renene.2014.07.032

[13] Mentis, D., Caralis, Karalis, G., Zervos, A., Howells, M., Taliotis, C., Bazilian, M. and Holger, R.(2016) Desalination Using Renewable Energy Sources on the Arid Islands of South Aegean Sea. Energy, 94, 262-272.

https://doi.org/10.1016/j.energy.2015.11.003

[14] Garci'a-Rodriguez, L. (2003) Renewable Energy Applications in Desalination State of the Art. Solar Energy, 75, 381-393. https://doi.org/10.1016/j.solener.2003.08.005

[15] Kasaeian, A., Rajaee, F. and Yan, W.M. (2018) Osmotic Desalination by Solar Energy: A Critical Review. Renewable Energy, 134, 1473-1490. https://doi.org/10.1016/j.renene.2018.09.038

[16] Ahmed, F.E., Hashaikeh, R. and Hilal, N. (2019) Solar Powered Desalination Technology, Energy and Future Outlook. Renewable Energy, 134, 1473-1490 https://doi.org/10.1016/j.desal.2018.12.002

[17] Kershman, S.A., Rheinländer, J., Neumann, T. and Goebel, O. (2005) Hybrid Wind/PV and Conventional Power for Desalination in Libya-GECOL's Facility for Medium and Small Scale Research at Ras Ejder. Desalination, 183, 1-12. https://doi.org/10.1016/j.desal.2005.04.021

[18] Ma, Q.F. and Lu, H. (2011) Wind Energy Technologies Integrated with Desalination Systems: Review and State-of-the-Art. Desalination, 277, 274-280. https://doi.org/10.1016/j.desal.2011.04.041

[19] Calise, F., Cappiello, L., Vanoli, R. and Vicidomini, M. (2019) Economic Assessment of Renewable Energy Systems Integrating Photovoltaic Panels, Seawater Desalination and Water Storage. Applied Energy, 253, Article ID: 113575. https://doi.org/10.1016/j.apenergy.2019.113575

[20] Weiner, D., Fisher, D., Moses, E.J., Katz, B. and Meron, G. (2001) Operation Expe- 
rience of a Solar- and Wind-Powered Desalination Demonstration Plant. Desalination, 137, 7-13. https://doi.org/10.1016/S0011-9164(01)00198-9

[21] Miranda, M.S. and Infield, D. (2003) A Wind-Powered Seawater Reverse-Osmosis System without Batteries. Desalination, 153, 9-16.

https://doi.org/10.1016/S0011-9164(02)01088-3

[22] Thomson, M. and Infield, D. (2003) A Photovoltaic-Powered Seawater Reverse-Osmosis System without Batteries. Desalination, 153, 1-8. https://doi.org/10.1016/S0011-9164(03)80004-8

[23] Mansour, T., Ismail, T., Ramzy, K. and Abd El-Salam, M. (2020) Energy Recovery System in Small Reverse Osmosis Desalination Plant: Experimental and Theoretical Investigations. Alexandria Engineering Journal. https://doi.org/10.1016/j.aej.2020.06.030

[24] Smith, D. (2000) Battery-Powered Desalter Relies on Unique Pressure Pump. International Desalination and Water Reuse Quarterly, 10, 18-22.

[25] Urrea, S.A., Reyes, F.D., Suárez, B.P. and Juan, A. (2019) Technical Review, Evaluation and Efficiency of Energy Recovery Devices Installed in the Canary Islands Desalination Plants. Desalination, 450, 54-63. https://doi.org/10.1016/j.desal.2018.07.013

[26] Bermudez, A. and Thomson, M. (2010) Modified Operation of a Small Scale Energy Recovery Device for Seawater Reverse Osmosis. Desalination and Water Treatment, 13, 195-202. https://doi.org/10.5004/dwt.2010.990

[27] Karassik, I.J., Messina, J.P., Cooper, P. and Charles, C. (2008) Pump Handbook. 4th Edition, the Mcgraw-Hill Companies, Inc., New York.

[28] Sassi, K.M. and Mujtaba, I.M. (2010) Simulation and Optimization of Full Scale Reverse Osmosis Desalination Plant. Computer Aided Chemical Engineering, 28, 895-900. https://doi.org/10.1016/S1570-7946(10)28150-6

[29] Caldera, U. and Breyer, C. (2018) The Role That Battery and Water Storage Play in Saudi Arabia's Transition to an Integrated 100\% Renewable Energy Power System. Journal of Energy Storage, 17, 299-310. https://doi.org/10.1016/j.est.2018.03.009

[30] Schunke, A.J., Hernandez Herrera, G.A., Padhye, L. and Berry, T.-A. (2020) Energy Recovery in SWRO Desalination: Current Status and New Possibilities. Frontiers in Sustainable Cities, 2, Article 9. https://doi.org/10.3389/frsc.2020.00009

[31] Liu, C.C.K., Jae-Woo, P., Migita, R. and Gang, Q. (2002) Experiments of a Prototype Wind-Driven Reverse Osmosis Desalination System with Feedback Control. Desalination, 150, 277-287. https://doi.org/10.1016/S0011-9164(02)00984-0 